\title{
PCR multiplex para identificação de isolados de Clostridium chauvoei e Clostridium septicum
}

[Multiplex PCR for identification of Clostridium chauvoei and Clostridium septicum]

\author{
R.A. Assis $^{1}$, F.C.F. Lobato $^{2 *}$, Z.I.P. Lobato $^{2}$, M.F. Camargos $^{1}$, R.A.P. Nascimento ${ }^{1}$, A.P.C. Vargas $^{3}$, \\ F.M. Salvarani ${ }^{2}$, F.A. Uzal ${ }^{4}$ \\ ${ }^{1}$ LANAGRO-MG - MAPA - Pedro Leopoldo, MG \\ ${ }^{2}$ Escola de Veterinária - UFMG \\ Caixa Postal 567 \\ 30123-970 - Belo Horizonte, MG \\ ${ }^{3}$ Universidade Federal de Santa Maria - Santa Maria, RS \\ ${ }^{4}$ California Animal Health and Food Safety Laboratory - San Bernardino, CA - EUA
}

\begin{abstract}
RESUMO
Padronizou-se uma técnica de reação em cadeia da polimerase múltipla (PCR multiplex) para detecção de Clostridium chauvoei e Clostridium septicum em culturas puras. Foram utilizados pares de iniciadores para segmentos específicos dos genes que codificam a flagelina de $C$. chauvoei e a toxina alfa de $C$. septicum. Para avaliação da PCR multiplex, foram testados 16 isolados clínicos de C. chauvoei e 15 isolados de $C$. septicum provenientes de ruminantes, quatro sementes vacinais de cada um desses agentes. Amostras de referência de ambos os microrganismos foram usadas como controle. Para avaliar a especificidade, DNAs genômicos dos seguintes microrganismos foram usados: C. sordellii, C. novyi tipo A, C. novyi tipo B, C. perfringens tipo A, C. haemolyticum, C. botulinum tipo D, Pseudomonas aeruginosa, Staphylococcus aureus, Enterobacter aerogenes, Escherichia coli e Salmonella typhimurium. Todos os isolados e sementes vacinais de C. chauvoei e C. septicum foram detectados pela técnica. Não foram observadas reações cruzadas com as outras espécies de clostrídios, outras espécies bacterianas ou entre $C$. Chauvoei e C. septicum. As menores concentrações de DNA de $C$. chauvoei e $C$. septicum detectadas foram $45 \mathrm{pg} / \mu \mathrm{l}$ e $30 \mathrm{pg} / \mu \mathrm{l}$, respectivamente. A PCR multiplex pode ser utilizada para a identificação específica de C. chauvoei e C. septicum em culturas puras.
\end{abstract}

Palavras-chave: PCR multiplex, identificação, Clostridium chauvoei, Clostridium septicum

\begin{abstract}
Multiplex PCR was optimized to detect Clostridium chauvoei and Clostridium septicum in pure cultures. In each reaction, a pair of primers for a specific segment of the flagellin gene of $\mathrm{C}$. chauvoei and a pair of primers for a specific segment of alpha toxin gene of $\mathrm{C}$. septicum were employed. Reference strains of both microorganisms were used as control. The multiplex PCR was evaluated by testing 16 clinical isolates of $\mathrm{C}$. chauvoei from ruminants, 15 clinical isolates of $\mathrm{C}$. septicum from ruminants and, four vaccine strains of each one of these agents. Reference strains of both microorganisms were used as control. To evaluate the specificity, genomic DNA of the following microorganisms was used: C. sordellii, C. novyi type $A, \mathrm{C}$. novyi type $B, \mathrm{C}$. perfringens type $A, \mathrm{C}$. haemolyticum, C. botulinum type $D$, Pseudomonas aeruginosa, Staphylococcus aureus, Enterobacter aerogenes, Escherichia coli, and Salmonella typhimurium. All the isolates and vaccine strains of $\mathrm{C}$. chauvoei and $\mathrm{C}$. septicum were positive by PCR assay and cross reactions were not observed with the other species of clostridia, the other bacterial species or amongst both investigated agents. The smallest concentrations of DNA detected
\end{abstract}

Recebido em 31 de julho de 2007

Aceito em 10 de maio de 2008

*Autor para correspondência (corresponding author)

E-mail: flobato@vet.ufmg.br 
PCR multiplex para identificação de isolados...

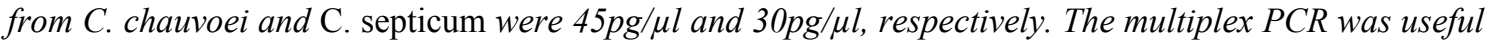
for the specific identification of $\mathrm{C}$. chauvoei and $\mathrm{C}$. septicum in pure cultures.

\section{Keywords: multiplex PCR, identification, Clostridium chauvoei, Clostridium septicum}

\section{INTRODUÇÃO}

Em várias partes do mundo, C. chauvoei e $C$. septicum são considerados os principais agentes responsáveis pelas mionecroses (Pinto e Abreu, 1992). No Brasil, ambos os microrganismos, atuando isoladamente ou em associação, são os mais freqüentemente relatados nos casos de carbúnculo sintomático e gangrena gasosa em bovinos (Baldassi et al., 1985). Apesar do grande número de casos de mionecroses no Brasil, a informação etiológica sobre essas doenças é escassa (Correa et al., 1980; Baldassi et al., 1985). A maioria dos diagnósticos é baseada apenas em achados clínicos e de necropsia (Assis et al., 2001), caracterizados por dificuldades de locomoção, depressão e recumbência e à necropsia, as áreas lesadas encontram-se edematosas, crepitantes e de coloração vermelhoenegrecida (Assis et al., 2002). O diagnóstico das mionecroses tradicionalmente tem sido feito baseando-se no cultivo e isolamento dos microrganismos envolvidos (Correa et al., 1980; Baldassi et al., 1985). Entretanto, o tempo necessário para o cultivo e isolamento, é de quatro dias a uma semana (Assis et al., 2001). Daí a importância da técnica de PCR multiplex, pela rapidez e precisão na diferenciação destes microrganismos, além da utilização de diferentes primers em uma mesma reação o que reduz os custos do teste (Macêdo et al., 2007).

Na PCR multiplex, em apenas uma reação, é possível detectar C. chauvoei e C. septicum, os quais podem ser encontrados em associação nos quadros de mionecroses nas diferentes espécies animais (Williams, 1977; Poonacha et al., 1982).

O objetivo deste estudo foi padronizar uma técnica de PCR multiplex para detectar o gene que codifica a flagelina de $C$. chauvoei e o gene que codifica a toxina alfa de $C$. septicum em culturas puras.

\section{MATERIAL E MÉTODOS}

Os DNAs genômicos usados foram obtidos a partir de 16 isolados de C. chauvoei (15 de bovinos e um de ovino) e 13 de C. septicum (de bovinos) com origens em diversos estados. Após certificado crescimento e pureza pelo Gram e, adicionalmente a certificação da identidade dos isolados por imunofluorescência direta (Pinto e Abreu, 1992), os clostrídios foram subcultivados em caldo cérebro-coração ${ }^{1}$ e incubados a $37^{\circ} \mathrm{C}$ em jarras de anaerobiose por 48 horas. As demais espécies bacterianas, listadas na Tab. 1, foram também subcultivadas em caldo cérebrocoração $^{1}$ em aerobiose a $37^{\circ} \mathrm{C}$ por 24 horas. Depois de verificado crescimento e pureza pelo Gram, os isolados foram novamente subcultivados em $15 \mathrm{ml}$ de caldo cérebrocoração $^{1}$ e incubadas como descrito acima. Finalmente, depois de verificado crescimento e pureza pelo Gram, os isolados foram processadas para a extração de DNA genômico conforme a metodologia descrita por Takeuchi et al. (1997).

Para padronização da PCR multiplex, a técnica de PCR para detecção do gene da flagelina de $C$. chauvoei foi realizada conforme Kojima et al. (2001), e para detecção do gene da toxina alfa de C. septicum, segundo Takeuchi et al. (1997). As concentrações de DNA foram determinadas conforme Sambrook et al. (1989), com a utilização de espectrofotômetro ${ }^{2}$ a 260-280nm de absorvância $\left(\mathrm{A}_{260-280}\right)$. Todos ensaios de PCR, foram realizados no termociclador Px2 Thermal Cycler $^{3}$. Para padronização da PCR multiplex, foram empregados um ciclo inicial de desnaturação a $94^{\circ} \mathrm{C} / 5 \mathrm{~min}$, seguido por 34 ciclos a $94^{\circ} \mathrm{C}$ por 1 minuto para desnaturação, $54^{\circ} \mathrm{C}$ por 1 minuto para anelamento e $72^{\circ} \mathrm{C}$ por 1 minuto para extensão. Foi também incluído, um ciclo final de extensão a $72^{\circ} \mathrm{C}$ por 7 minutos. Utilizaram-se os pares de oligonucleotídeos iniciadores: C. chauvoei- 516-senso (5' ATCGGAAACATGAGTGCTGC 3') e 516-antisenso (5' AGTCTTTATGCTTCCGCTAG 3') (Kojima et al., 2001) e C. septicum: senso- (5' AATTCAGTGTGCGGCAGTAG 3') e antisenso- (5' CCTGCCCCAACTTCTCTTTT 3') (Takeuchi et al., 1997). A PCR foi realizada em

\footnotetext{
${ }^{1}$ Difco - Sparks, EUA.

${ }^{2}$ Thermo Spectronic Model Genesys 10UV - Rochester, EUA

${ }^{3}$ Thermo Electron Corporation - Milford, EUA
} 
um volume final de $100 \mu$, usando tampão 1B$10 \mathrm{X}^{4}(500 \mathrm{mM} \mathrm{KCl}, 100 \mathrm{mM}$ Tris-Hcl pH 8,4, 1\% Triton X-100), 2,5mM de $\mathrm{MgCl}_{2}{ }^{5}, 10 \mathrm{pmol}$ de cada iniciador de C. chauvoei, $20 \mathrm{pmol}$ de cada iniciador de C. septicum, $0,25 \mathrm{mM}$ de cada $\mathrm{dNTPs}^{4}, 2,5 \mathrm{U}$ de $T a q$ polimerase ${ }^{5}$, água ultra pura $^{4}$, e 450ng e 300ng de DNA genômico de $C$. chauvoei e C. septicum, respectivamente. A especificidade analítica dos iniciadores foi verificada testando-se DNAs genômicos das demais espécies de clostrídios e das outras cinco espécies bacterianas (Tab. 1), nas mesmas condições descritas acima, com o uso de 450ng de DNA de cada um desses microrganismos. Foram realizadas PCR multiplex com DNAs genômicos de $C$. chauvoei e $C$. septicum separadamente para verificar a especificidade analítica dos iniciadores entre esses agentes. Em todas as reações foram utilizados controles positivo e negativo. Como controles positivos foram utilizados DNAs genômicos de $C$. chauvoei, amostra ATCC 10092, e de $C$. septicum, amostra ATCC 12464. Como controle negativo foram utilizados todos os reagentes da PCR sem os DNAs genômicos.

Tabela 1. Amostras de referências utilizadas na padronização da PCR multiplex

\begin{tabular}{|c|c|}
\hline Amostra & Origem \\
\hline Clostridium chauvoei & ATCC 10092 (controle positivo) \\
\hline Clostridium septicum & ATCC 12464 (controle positivo) \\
\hline Clostridium sordellii & ATCC 9714 \\
\hline Clostridium novyi tipo A & ATCC 19402 \\
\hline Clostridium novyi tipo B & ATCC 25758 \\
\hline Clostridium haemolyticum & ATCC 9650 \\
\hline Clostridium perfringens tipo A & ATCC 3624 \\
\hline Clostridium novyi tipo B & ATCC 25758 \\
\hline Clostridium haemolyticum & ATCC 9650 \\
\hline Clostridium botulinum tipo D & NCTC 8265 \\
\hline Pseudomonas aeruginosa & ATCC 27853 \\
\hline Staphylococcus aureus & ATCC 25923 \\
\hline Enterobacter aerogenes & ATCC 13048 \\
\hline Escherichia coli & ATCC 25922 \\
\hline Salmonella typhimurium & ATCC 14028 \\
\hline
\end{tabular}

$\mathrm{ATCC}=$ American type culture collection; $\mathrm{NCTC}=$ National collection of type cultures

Após o término da PCR, os produtos amplificados, separados pela eletroforese foram visualizados em gel de agarose a $1 \%$ corado com brometo de etídeo $(0,5 \mu \mathrm{g} / \mathrm{ml})$. $1 \mathrm{~kb}$ Plus DNA Ladder $^{4}$, foi usado como marcador de peso molecular. Para certificação da identidade dos produtos amplificados, uma amostra de $C$. chauvoei usada na produção de vacina e o isolado de $C$. septicum Itaperuna proveniente do estado do Rio de Janeiro foram novamente amplificados. As bandas correspondentes aos produtos da PCR de C. chauvoei e de $C$. septicum, foram cortadas do gel com auxílio de um bisturi estéril e purificadas separadamente usando-se o kit Wizard SV Gel ${ }^{5}$ e PCR Clean-Up System A9281 2 . Posteriormente os DNAs dessas

${ }^{4}$ Invitrogen - São Paulo, Brasil.

${ }^{5}$ Promega - Wisconsin, EUA amostras foram submetidas para seqüenciamento no Bioagro/UFV/Minas Gerais.

Para se determinar a menor concentração de DNA detectada pela técnica, foram realizadas diluições decimais $\left(10^{-1}\right.$ a $\left.10^{-6}\right)$, a partir de concentrações de 450ng/ $\mu \mathrm{l}$ e 300ng/ $\mu \mathrm{l}$ de DNA genômico das amostras de C. chauvoei - ATCC 10092 e C. septicum - ATCC 12464, respectivamente.

\section{RESULTADOS E DISCUSSÃO}

A PCR multiplex foi padronizada com 20 amostras de $C$. chauvoei (16 culturas puras provenientes de ruminantes e quatro sementes

\footnotetext{
${ }^{6}$ Invitrogen - São Paulo, Brasil

${ }^{7}$ Phoneutria - Belo Horizonte, Brasil
} 
usadas na produção de vacinas) e 19 de $C$. septicum (15 culturas puras provenientes de ruminantes e quatro sementes usadas na produção de vacinas). Todos os isolados clínicos desses agentes foram detectados pela PCR multiplex, na qual observou-se somente a amplificação dos produtos esperados de $516 \mathrm{pb}$ e $270 \mathrm{pb}$ de $C$. chauvoei e C. septicum, respectivamente. Não foram observadas reações cruzadas com as demais espécies de clostrídios, com as outras espécies bacterianas e entre $C$. chauvoei e C. septicum (Fig. 1). Em todas as reações, os controles positivo e negativo de $C$. chauvoei e C. septicum, mostraram-se também eficientes. Os produtos amplificados e purificados de C. chauvoei e C. septicum, tiveram sua identidade certificada pelo seqüenciamento. A seqüência da amostra Itaperuna, RJ de C. septicum, está disponível no GenBank sob o número de acesso AY589051.

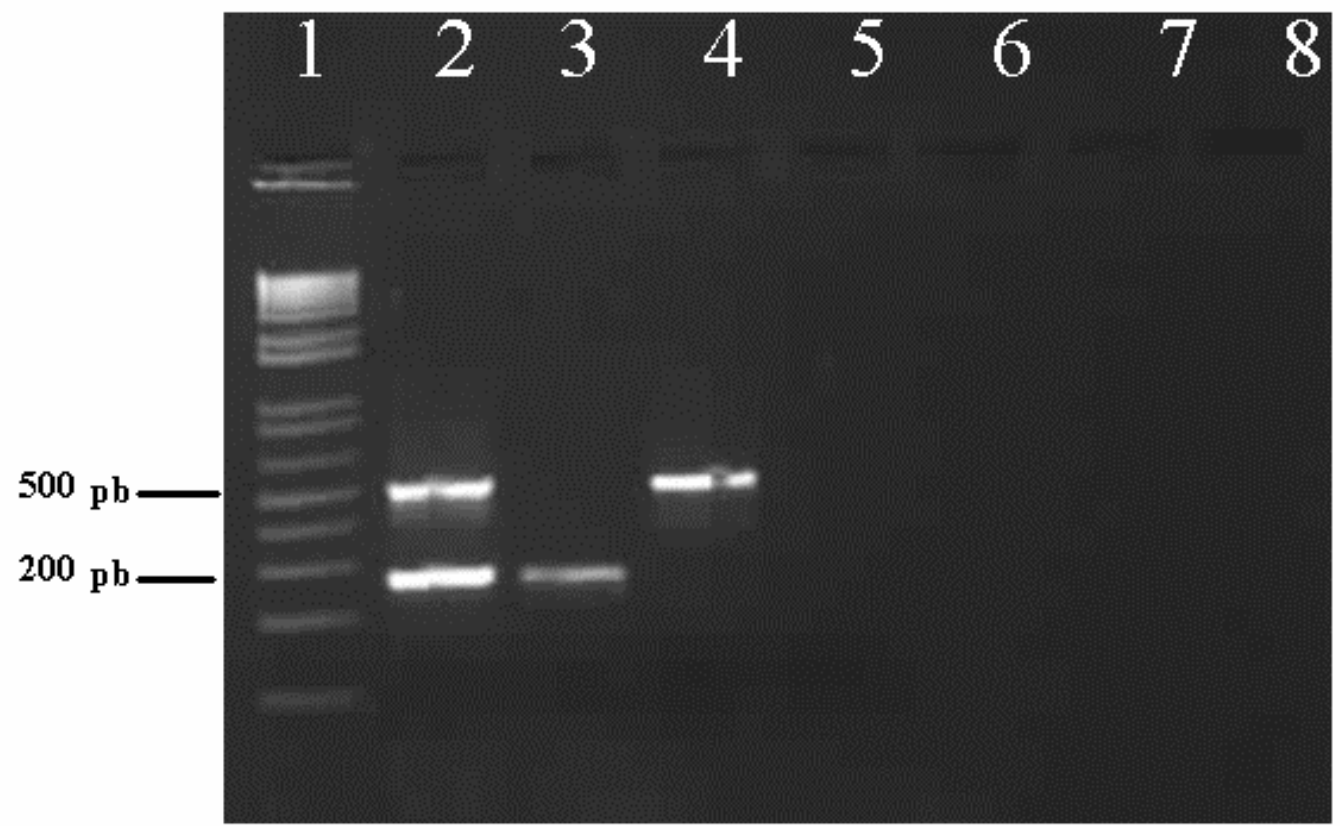

Figura 1. Eletroforese em gel de agarose da PCR multiplex de Clostridium chauvoei e Clostridium septicum. 1: marcador de peso molecular (1kb plus DNA Ladder, Invitrogen); 2: amplificação de cultura pura de C. chauvoei (estado de Minas Gerais) e cultura pura de C. septicum (estado do Rio Grande do Sul); 3: amplificação de C. septicum; 4: amplificação de. Chauvoei; 5: DNA genômico de C. sordellii; 6: DNA genômico de $C$. novyi tipo A; 7: DNA genômico de $C$. perfringens tipo A; 8: controle negativo.

Na figura 1, está demonstrada a amplificação de uma cultura de C. chauvoei, isolado no estado de Minas Gerais, e de uma cultura de C. septicum, isolado no estado do Rio Grande do Sul. Em adição, está representada a amplificação desses isolados, usando os respectivos DNAs genômicos separadamente. Também, são mostrados os resultados da PCR multiplex, usando DNAs genômicos de $C$. sordellii, $C$. novyi tipo A e C. perfringens tipo A.

As menores concentrações de DNA detectados da amostra ATCC 10092 de C. chauvoei e da amostra ATCC 12464 de C. septicum foram $45 \mathrm{pg} / \mu \mathrm{l}$ e $30 \mathrm{pg} / \mu 1$, respectivamente.

Em relação aos estudos de Takeuchi et al., 1997 e Kojima et al., 2001, não foi possível fazer comparação da sensibilidade entre os resultados relatados por esses autores e os deste trabalho, devido às diferentes metodologias adotadas. Neste estudo a menor quantidade de DNA, detectado por reação, foi determinada em picogramas. Takeuchi et al. (1997), determinaram a menor quantidade de DNA detectado por reação em UFC/ml e Kojima et al. (2001) em UFC. 
Relatos sobre o desenvolvimento de duas técnicas de PCR multiplex para detecção de $C$. chauvoei, C. septicum e outros clostrídios patogênicos com base no gene que codifica a flagelina foram feitos por Sasaki et al. (2002a,b). $\mathrm{Na}$ literatura disponível, entretanto, não foram encontrados descrição de PCR multiplex com base no gene da toxina alfa de $C$. septicum. A PCR multiplex mostrou-se também eficiente para detectar C. chauvoei e C. septicum, separadamente. Esta técnica complementará os procedimentos laboratoriais para o diagnóstico de $C$. chauvoei e $C$. septicum, e poderá melhorar significativamente a taxa de sucesso no diagnóstico das mionecroses no Brasil. Contudo, futuros trabalhos deverão ser realizados para se avaliar a eficiência da técnica na identificação de C. chauvoei e C. septicum diretamente dos espécimes clínicos de animais com suspeita de mionecroses.

\section{AGRADECIMENTOS}

À FAPEMIG e ao CNPq, pelo suporte financeiro. Ao Instituto PESAGRO - Rio de Janeiro, especialmente aos Drs. Rossiane Moura Souza e Milton Moreno. À Dra. Lúcia Baldassi (IBSP - São Paulo). À Dra. Akemi Kojima (NVAL - Kokubunji, Japão) e ao LANAGRO MG.

\section{REFERÊNCIAS BIBLIOGRÁFICAS}

ASSIS, R.A.; LOBATO, F.C.F.; DIAS, L.D. et al. Producción y evaluación de conjugados fluorescentes para diagnóstico de mancha $\mathrm{y}$ gangrena gaseosa. Rev. Med. Vet., v.82, p.68-70, 2001

ASSIS, R.A.; LOBATO, F.C.F.; MARTINS, N.E. et al. Surto de gangrena gasosa em bovinos. Rev. Port. Cienc. Vet., v.27, p.13-145, 2002.

BALDASSI, L.; HIPÓLITO, M.; CALIL, E.M.B. et al. Observações sobre a incidência de gangrena gasosa e carbúnculo sintomático durante 10 anos, 1970-79, no estado de São Paulo. Biológico, v.51, p.161-165, 1985.
CORREA, W.M.; CORREA, C.N.N.; LOPES, C.A.M. et al. Enfermidades por clostrídios 19691978 (clostridial diseases 1969-1978). Arq. Esc. Vet. UFMG, v.32, p.369-374, 1980.

KOJIMA, A.; UCHIDA, I.; SEKISAKI, T. et al. Rapid detection and identification of Clostridium chauvoei by PCR based on flagellin gene sequence. Vet. Microbiol., v.78, p.363-371, 2001.

MACÊDO, N.R.; MENEZES, C.P.L.; LAGE, A.P. et al. Detecção de cepas patogênicas pela PCR multiplex e avaliação da sensibilidade a antimicrobianos de Escherichia coli isoladas de leitões diarréicos. Arq. Bras. Med. Vet. Zootec., v.59, p.1117-1123, 2007.

PINTO, M.P.; ABREU, V.L.V. Comparação de técnicas para preparo de conjugados antiClostridium septicum e anti-Clostridium chauvoei. Arq. Bras. Med. Vet. Zootec., v.44, p.513-520, 1992.

POONACHA, K.B.; DONAHUE, J.M.; LEONARD, W.H. Clostridial myositis in a cat. Vet. Pathol., v.19, p.217-219, 1982.

SAMBROOK, J.; FRITSCH, E.F.; MANIATIS, T. Molecular Cloning: A laboratory manual. 2ed. New York: Cold Spring Harbor Laboratory, 1989.

SASAKI, Y.; KOJIMA, A.; AOKI, H. Phylogenetic analysis and PCR detection of Clostridium chauvoei, Clostridium haemolyticum, Clostridium novyi types A and B, and Clostridium septicum based on the flagellin gene. Vet. Microbiol., v.86, p257-267, 2002a.

SASAKI, Y.; KOJIMA, A.; KIKUCHI, E. et al. Multiplex PCR for direct detection of pathogenic clostridia in bovine clostridial infections. J. Vet. Med., v.55, p.889-893, 2002b.

TAKEUCHI, S.; HASHIZUME, N.; KINOSHITA, T. et al. Detection of Clostridium septicum hemolysin gene by polymerase chain reaction. J. Vet. Med. Sci., v.59, p.853-855, 1997.

WILLIAMS, B.M. Clostridial myositys in cattle: bacteriology and gross pathology. Vet. Rec., v.100, p.90-91, 1977. 